\title{
Sennosides Determination of Ethiopian Senna alexandrina Mill Accessions Bekri Melka Abdo*
}

Natural Product Research Laboratory, Wondo Genet Agricultural Research Center, Shashemene, Ethiopia

*Corresponding author: Bekri Melka Abdo, Natural Product Research Laboratory, Wondo Genet Agricultural Research Center, Shashemene, Ethiopia, Tel: +251911810857; E-mail: bekrimelka2003@yahoo.com

Received: September 15, 2017; Accepted: September 20, 2017; Published: September 26, 2017

Copyright: $\odot 2017$ Abdo BM. This is an open-access article distributed under the terms of the Creative Commons Attribution License, which permits unrestricted use, distribution, and reproduction in any medium, provided the original author and source are credited.

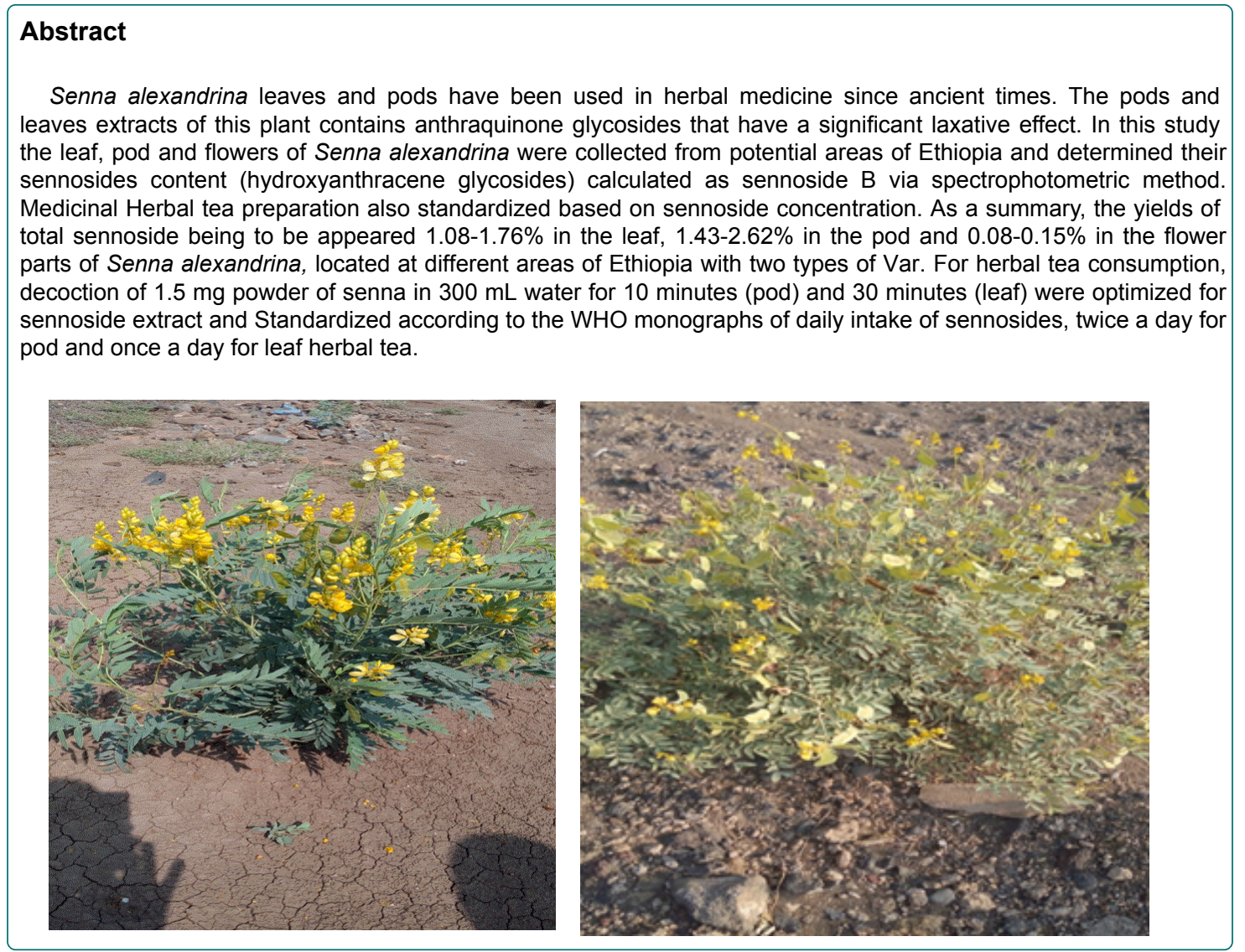

Keywords: Ethiopia; Laxative; Optimization; Senna alexandrina; Sennoside; Standardization

\section{Introduction}

Constipation is a common complaint in $1-6 \%$ of the middle-aged population and $20-80 \%$ of the elderly people. One of the most commonly used groups of drugs used in the correction of functional disorders of the digestive system, are laxatives [1]. The most widely used herbal remedies are containing anthraquinone derivatives [2], and the popular source are two species of Cassia Senna (Cassia acutifolia Delile. ), or Alexandrian senna (senna alexandrina Mill) and

Tinnevelly senna Cassia angustifolia Vahl .) with a family (Fabaceae/ Leguminosae). The active constituents in both senna leaf and fruit are dianthrone glycosides (hydroxyanthracene glycosides) principally sennosides A and B. There are also small amounts of aloeemodin and rhein 8-glucosides, mucilage, flavonoids, and naphthalene precursors [3].
Senna alexandrina is originated from Mali eastwards to Somalia and Kenya, much of it from wild plants. It is also native in Asia from the Arabian Peninsula to India and Sri Lanka. Two varieties are distinguished in Senna alexandrina. The first is var. obtusata (Brenan) Lock, restricted to Eritrea, Ethiopia, Somalia and northern Kenya, the second is var. alexandrina, which is the more widespread variety [4]. In Sudan, Ethiopia, Somalia and Kenya both leaves and pods are used as a purgative. Decoction of the pods is drunk to get rid of intestinal worms and to cure difficulties in breathing. The infusion of the pods is recommended as a purgative for pregnant women and also to suppress fever. An infusion of the leaves is drunk to overcome flatulence and convulsions and to stop nosebleeds.

However, Senna alexandrian shrubs are abundant in Ethiopia, not exploit the benefit obtained due to lack of standardization and product formulation. Characterization of location based phytochemicals is stringent for the reason that quantitative and qualitative variability of secondary metabolites in the plant through cultivation conditions and 
the time of harvesting [5]. Therefore, this work was performed to determine the sennosides content of Senna alexandrina accession. Quantitative analysis is performed by spectrophotometry. Thin-layer chromatography is employed for qualitative analysis for the presence of sennosides A and B [6].

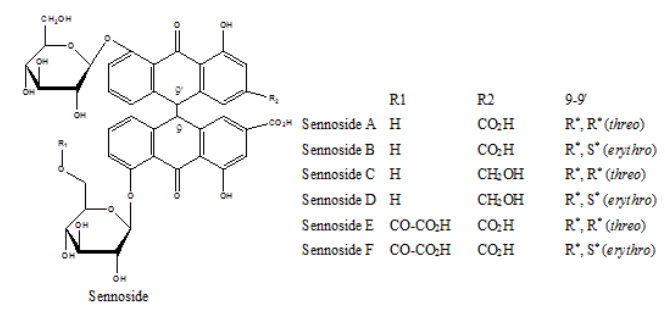

Figure 1: Hydroxyanthracene glycosides.

\section{Materials and Methods}

\section{Sample collection}

Senna (Senna alexandrina M.) samples were collected on mid of September 2016 from potential areas of eastern Ethiopia, particularly Dubti (410 m a.s.l, N 11 ${ }^{0} 46^{\prime \prime}$ E $\left.041^{\circ} 02 "\right)$, Logia (464 m a.s.l, N 11041" E

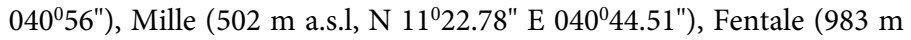
a.s.l, N $08^{0} 55^{\prime \prime}$ E $039^{\circ} 50^{\prime \prime}$ ) and Shinile (1086 m a.s.l, N 09067" E $\left.041^{\circ} 94^{\prime \prime}\right)$. Different parts of the plant (leave, pod and flower) were pinched independently. Each sample was dried on sun and pulverized through grinder and packed in plastic bag until extraction.

\section{Extraction and quantification}

Powdered sample $(0.5 \mathrm{~g})$ was refluxed for $1 \mathrm{hr}$ through superior extracting solvent $(99.7 \%$ methanol) [7]. The insoluble matter were filtered through Buchner funnel and made the volume to $250 \mathrm{~mL}$ with methanol. The standard of sennoside B in methanol solution was scanned through Cary 100 UV-VIS spectrophotometer at wave length range of $200-800 \mathrm{~nm}$ and selects $276 \mathrm{~nm}$ as a $\lambda$ max value. Samples were analyzed immediately after extraction in order to avoid possible chemical degradation by using UV-VIS spectrophotometer at $276 \mathrm{~nm}$ wavelength [8]. The experiments were carried out in a completely randomized design with three replications.

\section{Detection and visualization}

The presence of sennosides (hydroxyanthracene glycosides) in methanol extracts were detected by analytical grade TLC with a solvent system of N-Buthanol: Ethyl acetate: Water: Glacial Acetic Acid (8:8:6:1) ratio through a slight modification of the method described by French pharmacopeia. In order to visualize the spot $20 \% \mathrm{v} / \mathrm{v}$ solution of nitric acid was sprayed on the plate and heated the plate for $10 \mathrm{~min}$ at $120^{\circ} \mathrm{C}$. after cooling the plate $50 \mathrm{mg} / \mathrm{L}$ solution of potassium hydroxide in ethanol were sprayed.

\section{Herbal tea preparation}

Homogenized powder samples of leaf and pod were subjected to decoction by water with three concentrations viz. $1.5 \mathrm{mg} / 300 \mathrm{~mL}$ (sat
1), $1.5 \mathrm{mg} / 150 \mathrm{~mL}$ (sat 2) and $1.5 \mathrm{mg} / 100 \mathrm{~mL}$ (sat 3) for 10, 20 and 30 minutes. The prepared tea were filtered through muslin cloth and subjected to determine the total hydroxyanthracene glycosides in terms of sennoside B.

\section{Statistical analysis}

Significance difference of total hydroxyanthracene glycosides between different types of var., parts and location of the plant were analyzed by SAS, version 9 . Statistical significance was defined as $p<0.05$. The effects of saturation and decoction time on sennoside content of the prepared herbal tea were determined through response surface optimization method with central composite design.

\section{Results and Discussion}

The presence of sennosides in the methanol extract were detected by TLC through N-Buthanol: Ethyl acetate: Water: Glacial Acetic Acid (8:8:6:1) solvent system. Sennoside B was appeared at $\mathrm{Rf}$ value of 0.28 next to sennoside A (0.52) followed sennoside D (0.72) and then sennoside C (0.84) bottom to top position (Figure 2). The total percent of sennoside (hydroxyanthracene glycoside) were determined by spectrophotometric method and linearity of the measurement was evaluated by analyzing different concentrations of the standard sennoside B in methanol solution at $276 \mathrm{~nm}$ wavelength (Figure 3). The Beer Lambert's law was obeyed in the range concentration of $184-1474 \mu \mathrm{g} / \mathrm{mL}$ sennoside B and the correlation coefficient was found to be 0.999 with a regression equation $\mathrm{Y}=0.284 \mathrm{X}-0.011$ (Figure 4).

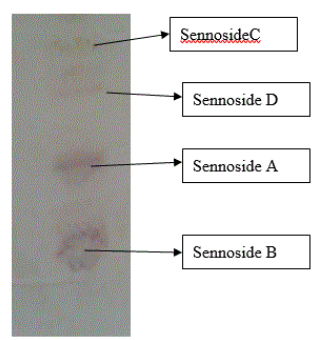

Figure 2: TLC profiles of methanol extracts of Senna alexandrina.

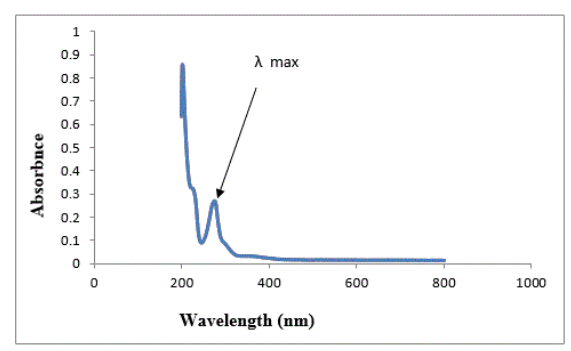

Figure 3: The UV-Vis spectra of sennoside B in methanol solution. 
Page 3 of 4

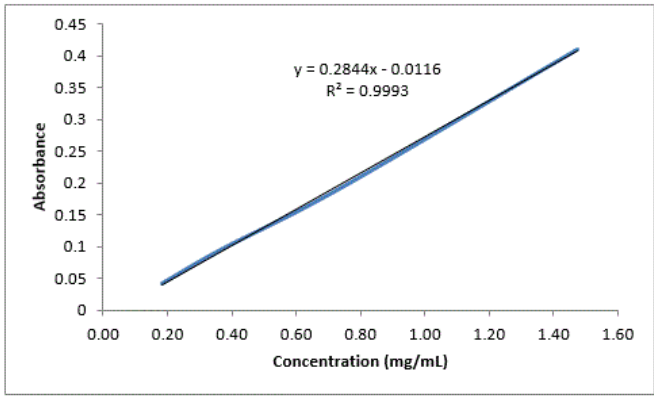

Figure 4: The plots of different concentration of sennoside B versus its absorbance.

From the analysis of variance, the types (short var. and long var.) of senna shrubs influenced the yields of sennoside in the leaf and pod part at $\mathrm{P}$ level $<0.01$ and $\mathrm{P}$ level $<0.001$ respectively. heir lowers did not show a statistical signi icance different in total percent of sennosides content at $\mathrm{P}$ level $<0.05$. he short var. senna shrub was superior in total percent of sennosides content with a mean value of $1.7 \%$ and $2.33 \%$ in the leaf and pod part respectively. he long var. senna shrub reached a sennosides content of $1.41 \%$ and $1.72 \%$ in the leaf and pod parts respectively (Table 1). Similar results were reported by kurkin and shmygareva [9] on yield of total anthracene derivatives in the leaf of Cassia acutifolia from Russia (1.21 to 1.88\%) interms of sennoside B determined by spectrophotometric method.

\begin{tabular}{|l|l|l|l|}
\hline \multirow{2}{*}{ Type } & \multicolumn{3}{|l|}{ Total Sennosides $(\%)$} \\
\cline { 2 - 4 } & Leaf & Pod & Flower \\
\hline Short var. & $1.70^{\mathrm{a}}$ & $2.33^{\mathrm{a}}$ & $0.13333^{\mathrm{a}}$ \\
\hline Long var. & $1.41^{\mathrm{b}}$ & $1.72^{\mathrm{b}}$ & $0.12000^{\mathrm{a}}$ \\
\hline LSD at $\mathrm{p}<0.05$ & 0.1867 & 0.2665 & 0.024 \\
\hline
\end{tabular}

Table 1: The effect of types (var.) on sennosides content of Senna alexandrina.

The locations were significantly affecting the yields of sennoside content for both types of senna shrubs in the leaf, pod and flower part. The short var. senna shrub collected from Fentale gave a higher percent of 1 sennosides content from the pod (2.62\%), next to Dubti $(2.30 \%)$ and followed Logia $(2.06 \%)$. The sennosides content from the leaf did not show a statistical significance difference among Dubti (1.73\%) and Fentale (1.77\%), but Logia with minimum mean value of $1.60 \%$ (Table 2 ). From the long var. senna shrub accession, Shinile is superior in sennosides content in the pod (2.08\%) and flower (0.15\%). Mile had front from the leaf $(1.61 \%)$ (Table 3 ).

\begin{tabular}{|l|l|l|l|l|}
\hline \multirow{2}{*}{ Location } & \multirow{2}{*}{ Altitude $(\mathbf{m})$} & \multicolumn{3}{|l|}{ Total Sennosides $(\%)$} \\
\cline { 3 - 5 } & & Leaf & Pod & Flower \\
\hline Dubti & 410 & $1.73 \mathrm{a}$ & $2.30 \mathrm{~b}$ & $0.13 \mathrm{a}$ \\
\hline Fentale & 983 & $1.76 \mathrm{a}$ & $2.62 \mathrm{a}$ & $0.14 \mathrm{a}$ \\
\hline Logia & 431 & $1.60 \mathrm{~b}$ & $2.06 \mathrm{c}$ & $0.13 \mathrm{a}$ \\
\hline
\end{tabular}

\begin{tabular}{|l|l|l|l|l|}
\hline LSD at $p<0.05$ & - & 0.093 & 0.0094 & 0.02 \\
\hline
\end{tabular}

Table 2: The influence of location on the sennosides content for short var. Senna alexandrina.

\begin{tabular}{|l|l|l|l|l|}
\hline \multirow{2}{*}{ Location } & \multirow{2}{*}{ Altitude $(\mathrm{m})$} & \multicolumn{4}{l}{ Total Sennosides $(\%) \mathrm{l}$} \\
\cline { 3 - 5 } & & Leaf & Pod & Flower \\
\hline Logia & 464 & $1.55 \mathrm{~b}$ & $1.64 \mathrm{~b}$ & $0.08 \mathrm{c}$ \\
\hline Mile & 502 & $1.61 \mathrm{a}$ & $1.43 \mathrm{c}$ & $0.13 \mathrm{~b}$ \\
\hline Shinile & 1086 & $1.08 \mathrm{c}$ & $2.08 \mathrm{a}$ & $0.15 \mathrm{a}$ \\
\hline LSD at $\mathrm{p}<0.05$ & - & 0.02 & 0.0094 & 0.02 \\
\hline
\end{tabular}

Means followed by the same letter under the same column are statistically non significant at $\mathrm{P}<0.05$ according to least significant difference (LSD) test

Table 3: The influence of location on the of sennosides content for long var. Senna alexandrina.

Generally, the sennosides content obtained from the pod comply the WHO and European standard limit which is $2.2 \%$ calculated as sennoside $B$. The sennosides content in the leaf was appeared to be less than the expected range of WHO [10] monograph limit which is $2.5 \%$ calculated as sennoside B. This is occurred due to the season of sampling which was lowering season, leads to shi t the secondary metabolite from leaf to lower and pod. Complimentary results were reported by Ratnayaka et al. [11] de lowering increases the sennoside A and $\mathrm{B}$ concentration in the leaf by $25 \%$ and also sennosides content maximize at the age of 90 days which is before lowering [12].

The herbal teas were made from leaf and pod ofSenna alexandrina through decoction in order to set the standard dose based on daily recommended value of total sennoside content calculated as sennoside B. The interaction of decoction time (temperature effect on extracting the active constituent) and the concentration of the applied herbal maters (solvent saturation effect on extracting the active constituent) were determined. The sennoside content of the herbal tea made from senna leaf increases as decreasing saturation and increasing decoction time (Figures 5 and 6). The sennoside yield increase as decreasing saturation and decoction time of the tea prepared from senna pod Figures 7 and 8.

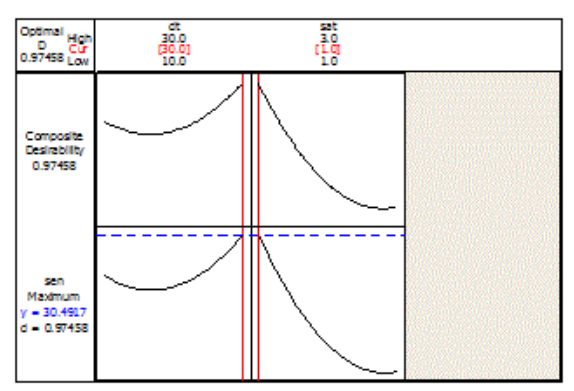

Figure 5: Optimization plots of leaf tea. 
Citation: Abdo BM (2017) Sennosides Determination of Ethiopian Senna alexandrina Mill Accessions. Nat Prod Chem Res 5: 293. doi:

Page 4 of 4

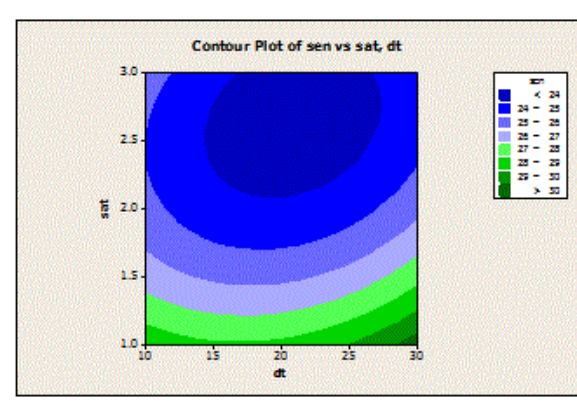

Figure 6: Contour plots of leaf tea.

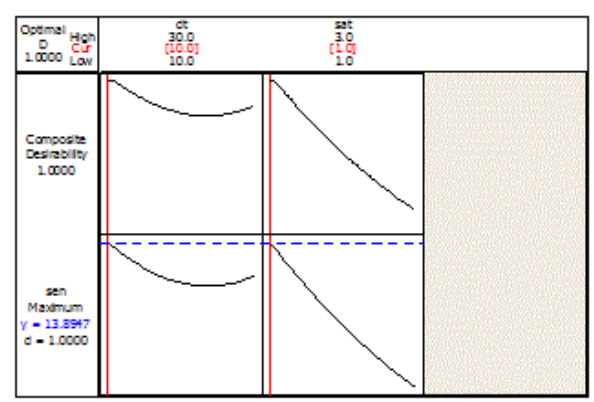

Figure 7: Optimization plots of pod tea .

Sen: sennoside; sat: saturation; dt: decoction time.

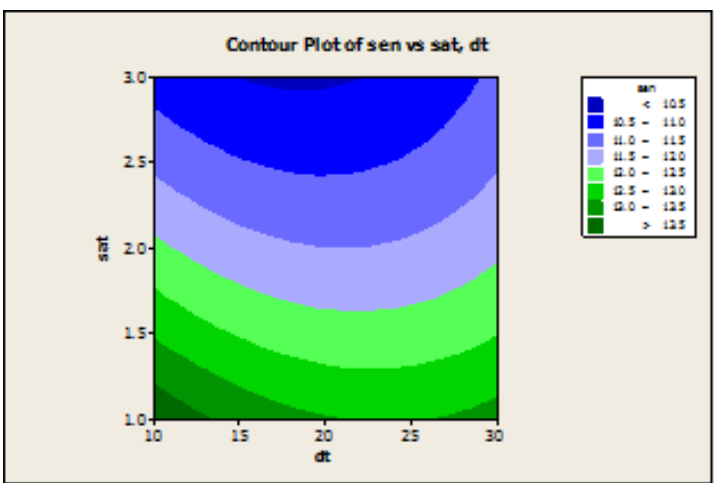

Figure 8: Contour plots of pod tea.

Sen: sennoside; sat: saturation; dt: decoction time.

\section{Conclusion}

This work was done on collecting Senna alexandrina leaf, pod and flower from potential areas of Ethiopia with acquiring two types (short var. and long var. shrubs) from five locations and designed to determine the sennosides content with comparing between types of var., parts and location of the plant. A spectrophotometric method was used to determine the total sennosides (hydroxyanthracene glycosides) calculated as sennoside B. As of the abundance of Senna alexandrina Mill in Ethiopia, the active ingredients were differs by the existing location, types of var. and parts of the plant. For herbal tea

consumption, $1.5 \mathrm{mg}$ powder of senna per $300 \mathrm{~mL}$ water decoction for 10 and 30 minutes were set twice a day and once a day for pod and leaf respectively.

\section{Acknowledgment}

My sincere gratitude is given to Wendo Genet Agricultural Research Center for funding this work and Abebe Shanko for his unreserved contribution.

\section{References}

1. Werner RD, Merz AD (2007) Committee on Herbal Medicinal Products (HMPC).

2. Kurkin VA (2009) Fundamentals of Phytotherapy: Textbook for students of pharmaceutical universities.

3. Bruneton J (1995) Pharmacognosy, phytochemistry, medicinal plants. Lavoisier Publishing.

4. Bosch CH (2007) PROTA (Plant Resources of Tropical Africa/Ressources végétales de l'Afrique tropicale). Schmelzer GH, Gurib-Fakim A (eds.), Wageningen, Netherlands.

5. Dewick PM (2001) Front Matter and Index. Medicinal Natural Products: A Biosynthetic Approach. (2nd edn).

6. European Pharmacopoeia (1995) Strasbourg, Council of Europe. (2nd edn).

7. Upadhyay A, Nayak PS, Dwivedi SK, Rao S (2011) HPTLC densitometric quantification of Sennosides from Cassia angustifolia. Gene Plant Physiol 1: 1-2.

8. Tarkase KN, Danve AV (2015) Development and Validation of Spectrophotometric Method for Simultaneous Estimation of Aloin and Sennoside in Suppository Dosage Form. Int J Pharm Sci Rev Res 31: 195-199.

9. Kurkin VA, Anna AS (2014) The development of new approaches to standardization of Cassia acutifolia leaves. J Pharmacog Phytochem 3: 163-167.

10. World Health Organization (1999) WHO monographs on selected medicinal plants. World Health Organization.

11. Ratnayaka HH, Meurer-Grimes B, Kincaid D (2002) Sennoside yields in Tinnevelly senna affected by deflowering and leaf maturity. Hort Sci 37: 768-772.

12. Upadhyay A, Nayak PS, Khan NA (2011) Sennoside contents in Senna (Cassia angustifolia Vahl.) as influenced by date of leaf picking, packaging material and storage period. J Stored Prod Postharv Res 2: 97-103. 